Вахитов Роман Наильевич

аспирант кафедры экономики

Удмуртского государственного университета, руководитель

АНО «Центр инвестиционного развития УР»

\section{МЕХАНИЗМ ГОСУДАРСТВЕННО- ЧАСТНОГО ПАРТНЕРСТВА И ЕГО РОЛЬ В РАЗВИТИИ РЕГИОНА}

Аннотация:

Государственно-частное партнерство является незаменимым механизмом развития инфраструктуры в регионе, особенно в условиях ограниченности бюджетного финансирования. Предпринятое исследование может способствовать повышению качества оказываемых населению услуг Предлагаются методические рекомендации, направленные на развитие государственно-частного партнерства на регчональном уровне.

Ключевые слова:

государственно-частное партнерство, стратегия развития региона, инвестиционный климат, частный партнер, публичный партнер.
Vakhitov Roman Nailyevich

PhD student, Economics Department, Udmurt State University, Head of Centre of Investment Development, Udmurt Republic

\section{MECHANISM OF PUBLIC-PRIVATE PARTNERSHIP AND ITS ROLE IN THE REGIONAL DEVELOPMENT}

Keywords: public-private partnership, regional development strategy, investment climate, private partner, public partner.

Государственно-частное партнерство (ГЧП) сегодня является значимым механизмом развития инфраструктуры в регионе. Он особенно важен в условиях ограниченности бюджетных средств и необходимости решения насущных социально-экономических проблем. Изучение мирового опыта подтверждает возможность снижения нагрузки на региональные и местные бюджеты за счет использования данного инструмента. Этот процесс зависит от активности органов власти и управления и может составлять ориентировочно 10-20 \% от расходов. Следует отметить, что помимо уменьшения бюджетной нагрузки указанный механизм позволяет повысить качество оказываемых населению услуг, что достигается в том числе за счет привлечения инвесторов к решению тех или иных задач. Этому препятствует недостаточная теоретическая и методическая разработанность вопросов развития государственно-частного партнерства на региональном уровне, что подтверждает актуальность проводимых нами исследований.

Прежде всего имеет смысл обратиться к определению рассматриваемого механизма. В федеральном законе от 13.07.2015 г. № 224-Ф3 отмечается, что государственно-частное партнерство - юридически оформленное на определенный срок и основанное на объединении ресурсов, распределении рисков сотрудничество публичного партнера, с одной стороны, и частного партнера, с другой стороны, которое осуществляется на основании соглашения о государственно-частном партнерстве, в целях привлечения в экономику частных инвестиций, обеспечения органами государственной власти доступности товаров, работ, услуг и повышения их качества [1].

Несмотря на все преимущества и очевидные выгоды государственно-частного партнерства, к сожалению, оно не получило необходимого для решения региональных проблем уровня развития. Более чем в половине субъектов РФ степень развитости сореры ГЧП ниже средней (менее 50 \% от эталонного показателя), в 45 субъектах она не превышает и 35 \%. При этом показатель, которого нужно достигнуть к 2018 г., составляет 70 \% [2].

В настоящее время Удмуртская Республика занимает 13-е место в рейтинге регионов в области развития государственно-частного партнерства. Если рассмотреть составляющие этого рейтинга, то по опыту реализации проектов ГЧП Удмуртская Республика занимает 10-е место, по качеству институциональной среды - 14-е [3]. Лидирующие позиции региона среди других субъектов Федерации связаны прежде всего с реализацией концессионного проекта «Строительство и эксплуатация на платной основе мостовых переходов через реку Кама и реку Буй у города Камбарка». Это уникальный проект с объемом финансирования 13 млрд р., где средства инвестора составили 72 \%, бюджета Удмуртии - менее 10 \%, из Инвестиционного фонда Российской Федерации получено 2,5 млрд р. 
Есть и другие реализуемые проекты, которые позволяют Удмуртской Республике сохранять лидирующие позиции в области государственно-частного партнерства, в том числе «Строительство фризкультурно-оздоровительного комплекса "Гулливер"», «Строительство спортивного комплекса в деревне Пирогово», «Строительство многофункционального спортивного центра в городе Сарапуле», «Реконструкция действующих канализационных очистных сооружений ОАО "Удмуртская птицефабрика"», «Туристско-рекреационный кластер "Камский берег" Удмуртской Республики».

В Стратегии социально-экономического развития Удмуртской Республики на период до 2025 г. обозначена существенная роль государственно-частного партнерства в решении региональных проблем [4]. В соответствии с федеральным законом от 28.06.2014 г. № 172-Ф3 «О стратегическом планировании в Российской Федерации» ведется работа по подготовке Стратегии социально-экономического развития региона до 2030 г., которая должна быть завершена в срок до 01.01.2019 г. Здесь рассматриваемому механизму уделено еще более пристальное внимание: будут указаны потребности территории в улучшении инфрраструктуры, а также приоритетность реализации инфраструктурных проектов. Кроме того, в Стратегии необходимо найти точки роста рынка проектов ГЧП, способные привести к существенному увеличению их числа.

Вместе с тем до принятия Стратегии социально-экономического развития Удмуртской Республики до 2030 г. для сохранения и укрепления позиций региона среди других субъектов Российской Федерации в области государственно-частного партнерства необходимы дополнительные меры, направленные на формирование действенной нормативно-правовой базы, развитие организационной инфраструктуры, активную работу с инвесторами и др. Эти усилия должны не только быть согласованы с политикой страны, но и основываться на общемировых тенденциях. К примеру, в Рекомендациях о принципах государственного управления по развитию государственно-частного партнерства Организации экономического сотрудничества и развития (Organisation for Economic Co-operation and Development - OECD) отмечается необходимость соблюдения следующих принципов:

- установить ясную, предсказуемую и легитимную институциональную основу при поддержке компетентных и хорошо обеспеченных ресурсами проектов;

- определить выбор государственно-частного партнерства по соотношению цены и качества;

- использовать бюджетный процесс прозрачно, чтобы минимизировать финансовые риски и гарантировать целостность процесса закупок [5].

С учетом этого мы сфрормулировали необходимые условия, направленные на формирование в регионе действенной нормативно-правовой базы, развитие организационной инфраструктуры, активную работу с инвесторами и др. (рисунок 1).

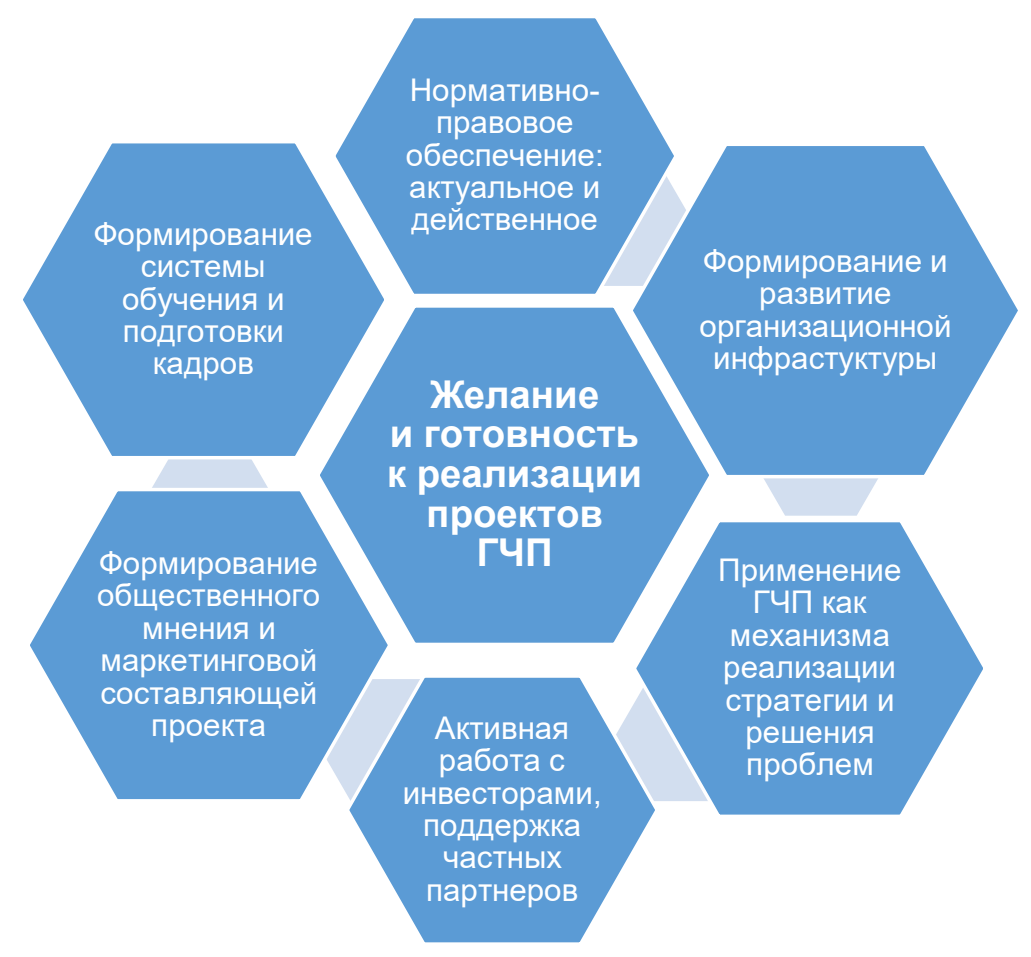

Рисунок 1 - Условия для развития механизма ГЧП в регионе

Также мы предлагаем методические рекомендации по развитию в регионе инструмента ГЧП. 
1. Государственно-частное партнерство является важным и эффективным механизмом в рамках социально-экономического развития территории, а также способом реализации региональной инвестиционной политики, стимулирующей улучшение инфраструктуры. Считаем целесообразным разработать инвестиционный план на основе потребностей населения, а также приоритетности инфраструктурных проектов, при этом особенно важно учитывать рациональное использование бюджетных средств, выгоды для инвестора и общества в целом.

По данным Центра развития государственно-частного партнерства, в большей степени реализуются проекты в коммунальной сфрере - 72 \%. Кроме того, отмечается, что российский рынок проектов ГЧП вышел на устойчивый рост по числу проектов и объему инвестиций. Так, на 873 проекта приходится 640 млрд р. привлеченных средств. В сфере культуры в рамках ГЧП осуществляются 33 проекта с объемом вложений 2,5 млрд р. [6].

В целях изучения мнения экспертов (57 опрошенных) о состоянии и перспективах государственно-частного партнерства в Удмуртской Республике, проблемах и мерах по его развитию проведено исследование, результаты которого представлены в таблице 1. На основании оценок специалистов и Стратегии социально-экономического развития нужно определить проблемы, решаемые посредством привлечения инвестора к реализации проектов, и, соответственно, приоритетные сореры внедрения механизма ГЧП в регионе.

Таблица 1 - Приоритетные направления для реализации проектов ГЧП

\begin{tabular}{|l|c|}
\multicolumn{1}{|c|}{ Направление } & $\begin{array}{c}\text { Доля экспертов, } \\
\text { отметивших направление, \% }\end{array}$ \\
\hline $\begin{array}{l}\text { Социальная сорера, объекты здравоохранения, образования, } \\
\text { культуры, спорта, туризма, санаторно-курортного лечения }\end{array}$ & 95 \\
\hline Транспорт, дороги, мосты & 75 \\
\hline Объекты, предназначенные для благоустройства территории & 57 \\
\hline Объекты обращения с твердыми коммунальными отходами & 53 \\
\hline Аэропорты и порты & 34 \\
\hline Объекты социального обслуживания населения & 32 \\
\hline Объекты очистки сточных вод & 43 \\
\hline Объекты тепло-, газо-, электроснабжения & 12 \\
\hline $\begin{array}{l}\text { Объекты по производству, передаче и распределению } \\
\text { электрической энергии }\end{array}$ & 6 \\
\hline
\end{tabular}

2. Необходимо осознать, что сам инструмент государственно-частного партнерства предполагает организацию эффективного взаимодействия с инвестором, у которого есть свои интересы. Это означает, что проект ГЧП должен быть сбалансирован по рискам и иметь привлекательность для инвестора, т. е. оправдывать его ожидания.

На уровне субъектов РФ традиционно лидируют следующие риски: низкая степень взаимного доверия власти и бизнеса, недостаток долгосрочного фринансирования, слабая законодательная база и др. По результатам опроса экспертов в Удмуртской Республике выявлены основные трудности при реализации проектов ГЧП, которые приведены в таблице 2.

Таблица 2 - Проблемы при реализации проектов ГЧП

\begin{tabular}{|l|c|}
\hline \multicolumn{1}{|c|}{ Проблема } & $\begin{array}{c}\text { Доля экспертов, } \\
\text { отметивших направление, \% }\end{array}$ \\
\hline Низкий уровень взаимного доверия власти и бизнеса & 82 \\
\hline Политическая & 42 \\
\hline Организационная & 35 \\
\hline Финансовая & 27 \\
\hline Правовая & 12 \\
\hline
\end{tabular}

Крайне важно на региональном уровне уметь корректно распределять и гармонизировать риски между публичным и частным партнерами, поскольку это не только является фрактором напряженности и недоверия, но и влияет на удорожание проекта. Такая работа требует от органов государственной власти иного рода деятельности, которая ранее не осуществлялась, - умения воспринимать потребности и интересы частного партнера, находить компромиссы. Это предполагает активизацию поиска дополнительных форм господдержки инвесторов, в том числе финансирование инфраструктурных проектов из средств регионального инвестиционного фонда; предоставление льготы по налогу на прибыль организаций; освобождение от налога на имущество; субсидирование части затрат по оплате процентов по кредитам и лизингу, полученным в целях реализации инвестиционных проектов; выделение земельных участков в аренду без торгов; а также информационную и организационную поддержку. 
3. Следует определить принципиальные параметры проекта государственно-частного партнерства, выбрать схему его реализации и законодательные акты, регулирующие процесс (рисунок 2). В связи с многообразием вариантов взаимодействия государства и частного сектора как в зарубежном опыте использования ГЧП, так и в отечественном очень важно установить первичную схему, наиболее адекватно отражающую интересы участников, на основании которой осуществляется выбор юридических норм.

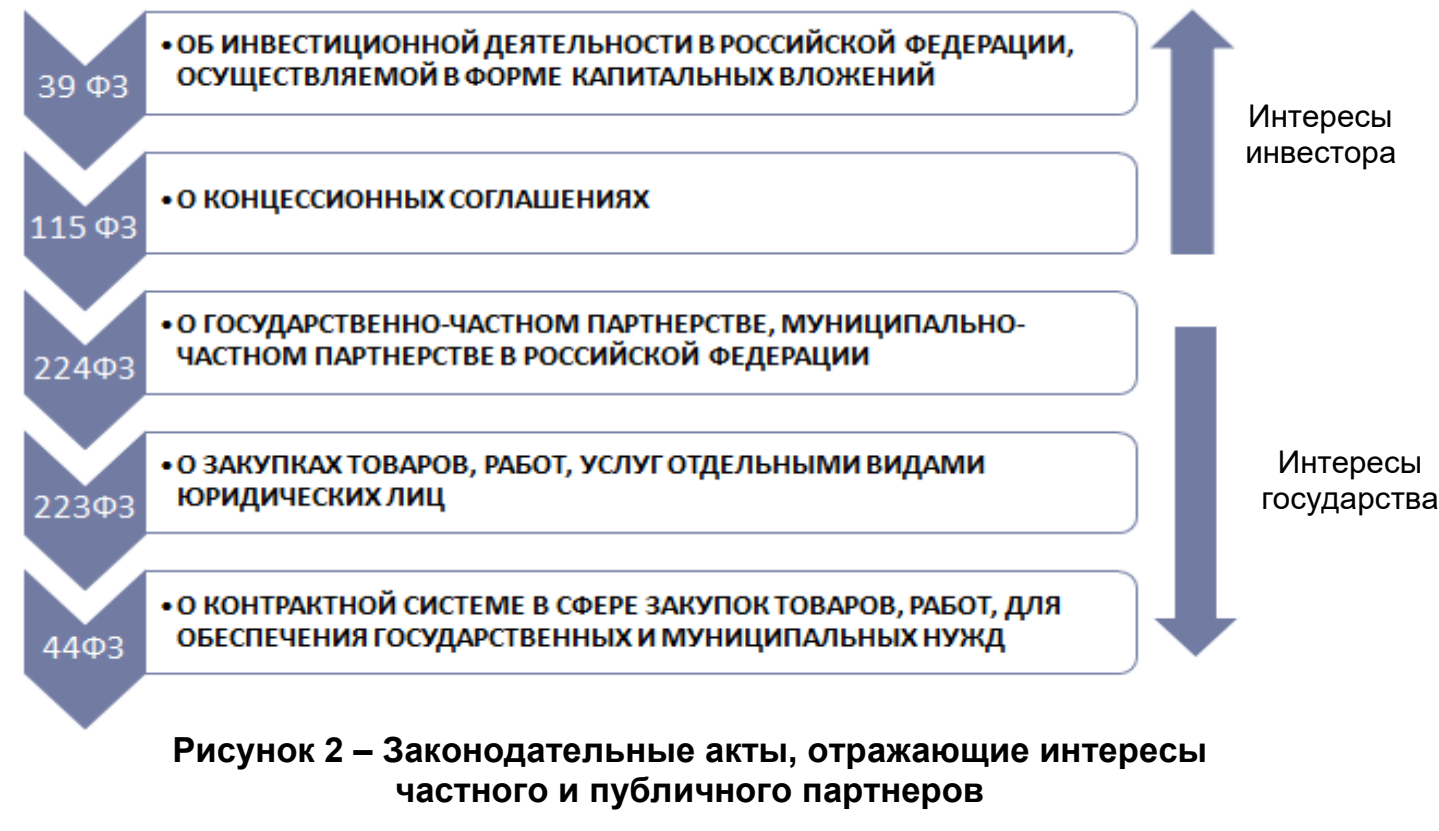

Целесообразно оценить эффективность затрат и распределения рисков при выборе варианта структурирования и финансирования проекта государственно-частного партнерства.

4. Необходимо детально проанализировать общественное мнение и маркетинговую составляющую проекта. К сожалению, недооцениваются вопросы, связанные с восприятием обществом тематики и конкретных проектов ГЧП. Важно учитывать политическую и социальную чувствительность населения к введению платы за пользование объектом государственно-частного партнерства, что предполагает соответствующие исследования и разъяснительную работу с гражданами. Данный шаг предусматривает поиск и предварительную обработку информации о проекте, оценку его сильных и слабых сторон, изучение общественного мнения и рынка в целях определения целевого сегмента, продвижение проекта.

5. В регионе необходимо сформировать систему обучения и подготовки кадров по тематике государственно-частного партнерства. В настоящее время идет работа над созданием профессионального и образовательного стандарта специалиста по ГЧП. В профессиональном стандарте определены требования к функциям и опыту специалистов, в образовательном - предложен профиль «управление проектами ГЧП» в направлении «менеджмент» [7]. Профртандарт и обучение помогут подготовить грамотных экспертов для реализации проектов в данной сфере.

В Удмуртии проводится системная работа по обучению в области государственно-частного партнерства. В 2015 г. подписано соглашение о практико-ориентированной подготовке руководителей и специалистов в этой сфере между правительством республики, Удмуртским государственным университетом и ЗАО «Транспроект Групп». В указанном образовательном учреждении создана базовая кафедра «Государственно-частное партнерство» как интегрированная образовательная структура УдГУ и автономной некоммерческой организации «Центр инвестиционного развития Удмуртской Республики». Регулярно ведутся курсы повышения квалификации, открыта магистратура «Управление проектами государственно-частного партнерства».

Таким образом, предлагаемые рекомендации можно применять в практической деятельности органов региональной власти в целях повышения инвестиционной привлекательности региона и реализации стратегии.

\section{Ссылки:}

1. О государственно-частном партнерстве, муниципально-частном партнерстве в Российской Федерации и внесении изменений в отдельные законодательные акты Российской Федерации [Электронный ресурс] : федер. закон от 13 июля 2015 г. № 224-Ф3. Доступ из справ.-правовой системы «КонсультантПлюс». 
2. Региональный ГЧП-стандарт : методические рекомендации по развитию институциональной среды в сфере государственно-частного партнерства в субъектах РФ. М., 2014.

3. Развитие государственно-частного партнерства в России в 2015-2016 гг. Рейтинг регионов по уровню развития ГЧП : исследование. М., 2016. 36 с.

4. Стратегия социально-экономического развития Удмуртской Республики на период до 2025 г. [Электронный ресурс] : утверждена законом Удмуртской Республики от 9 окт. 2009 г. № 40-P3. URL: http://economy.udmurt.ru/prioriteti/ser/strategia/strategia2025.pdf (дата обращения: 04.02.2017).

5. Recommendation of the Council on Principles for Public Governance of Public-Private Partnerships [Электронный ресурс]. URL: https://www.oecd.org/governance/budgeting/PPP-Recommendation.pdf (дата обращения: 04.02.2017).

6. Объем инвестиций в проекты ГЧП в культуре составил 2,5 млрд р. [Электронный ресурc]. URL: http://pppcenter.ru/29/novosti/pppcenter-news/obem-investiczij-v-sfere-kulturyi-sostavil-2,5-mlrd.-rublej.html (дата обращения: 08.02.2017).

7. Мереминская Е. Специалисты по партнерству с государством заработают по профстандарту [Электронный ресурс]. URL: http://www.vedomosti.ru/economics/articles/2016/10/24/662096-spetsialisti-partnerstvu-gosudarstvom (дата обращения: 06.02.2017)

\section{References:}

Development of public-private partnership in Russia in 2015-2016. Regions rating on development level of public-private partnership: research 2016, Moscow, 36 p., (in Russian).

Mereminskaya, E 2017, Specialists in partnership with the government will earn money according to professional standard, viewed 06 February 2017, <http://www.vedomosti.ru/economics/articles/2016/10/24/662096-spetsialisti-partnerstvu-gosudarstvom>, (in Russian).

Recommendation of the Council on Principles for Public Governance of Public-Private Partnerships 2017, viewed 04 February 2017, <https://www.oecd.org/governance/budgeting/PPP-Recommendation.pdf>. 